\title{
The Effects on the Number of Patients Visiting the Emergency Units: Comparison Study Before and During COVID-19 Pandemic in Saudi Arabia
}

\author{
Abdelhakim Abdelhadi (iD \\ Engineering Management Department, \\ Prince Sultan University, Riyadh, Saudi \\ Arabia
}

Background: The number of patients attending emergency departments (EDs) fell dramatically in 2020, during the COVID-19 pandemic, compared with similar periods in 2019 or 2018, and healthcare providers have had to adjust to this change. The aim of this study was to compare the number and type of patients attending a hospital emergency unit before and during the COVID-19 pandemic in order to avoid the impact of any difference on the community's healthcare and on healthcare providers.

Methods: This study assessed differences in the numbers of patients attending the emergency department in 2018, 2019 and 2020, and then determined whether a particular patient type accounted for any such difference. An open-source data repository was accessed to collect the data targeting a private hospital in Riyadh city, the capital of Saudi Arabia. Descriptive statistics and a paired $t$-test were used to verify the level of variations in the number of patients attending the emergency rooms.

Results: Results showed no statistically significant difference in the number of patients attending the emergency department between 2018 and 2019, while a noticeable drop was found in the number of patients attending the department between 2019 and 2020.

Conclusion: The reduction in the number of patients attending the emergency department was found in some but not all patient types. These conclusion highlight variations in ED attendance of which hospital management should be aware so that action can be taken to avoid negative consequences.

Keywords: emergency room, COVID-19, World Health Organization

\section{Introduction}

In Saudi Arabia and elsewhere, the utilization of emergency departments (EDs) has increased in recent years ${ }^{1,2}$ an observation which has been attributed to non-urgent patients comprising approximately $50 \%$ of all ED cases. ${ }^{3,4}$ In Saudi Arabia, non-urgent patients reported multiple reasons for attending the ED such as convenience and rapid access, and the perception that they will receive better care. ${ }^{5}$ These factors can lead to ED overcrowding with consequences such as increased waiting time, impaired patientcentered care, and disrupted evaluation and treatment. ${ }^{6,7}$ The COVID-19 disease outbreak that first surfaced in Wuhan, China, in December 2019, has had a major impact globally, affecting almost every country. ${ }^{8}$ Emergency departments have provided a first point of contact for patients with or without the COVID virus symptoms and have been most heavily impacted by this outbreak. They have played an important role in identifying patients infected with the virus and isolating them for further treatments, highlighting
Correspondence: Abdelhakim Abdelhadi Email abdelhadi@psu.edu.sa 
the critical nature of emergency medicine in public health. We studied the volume of patients arriving at an ED in a private hospital in the Kingdom of Saudi Arabia. We found that the number of patients attending the emergency room fell compared to previous years, perhaps due to factors such as the government-imposed curfew, or personal decisions by the public to minimize the chance of infection, based on a perception of any medical facility being a source of such infection. In this paper, we discuss the types of patient that contributed to decreased emergency department attendance during this period and the consequences of this decrease on the community or the patients themselves.

The first indication of the COVID-19 disease outbreak was in the city of Wuhan, Hubei Province, on December 2019 when the Chinese government informed the World Health Organization (WHO) China country office about a cluster of
41 patients with a new respiratory infection. On 11 January 2020, the Chinese authority informed the WHO that this infection was due to a novel coronavirus. ${ }^{9}$ In Saudi Arabia, hospital EDs were prepared to some extent since isolation areas had been created within those departments when the SARS virus outbreak occurred in $2003 .{ }^{10,11}$ On a normal day, the ED is manned by three shifts of doctors and nurses over a $24-\mathrm{hr}$ period. The private hospital used in this was therefore prepared to receive a higher number of patients than usual due to the increasing number of COVID-19 infections. Figure 1 shows the number of confirmed cases in the Kingdom of Saudi Arabia since January 2020 (https://www. worldometers.info/coronavirus/).

Figure 2 indicates a decline in the number of patients attending the ED between January 2020 and September 2020 compared to the same period in 2018 and 2019.

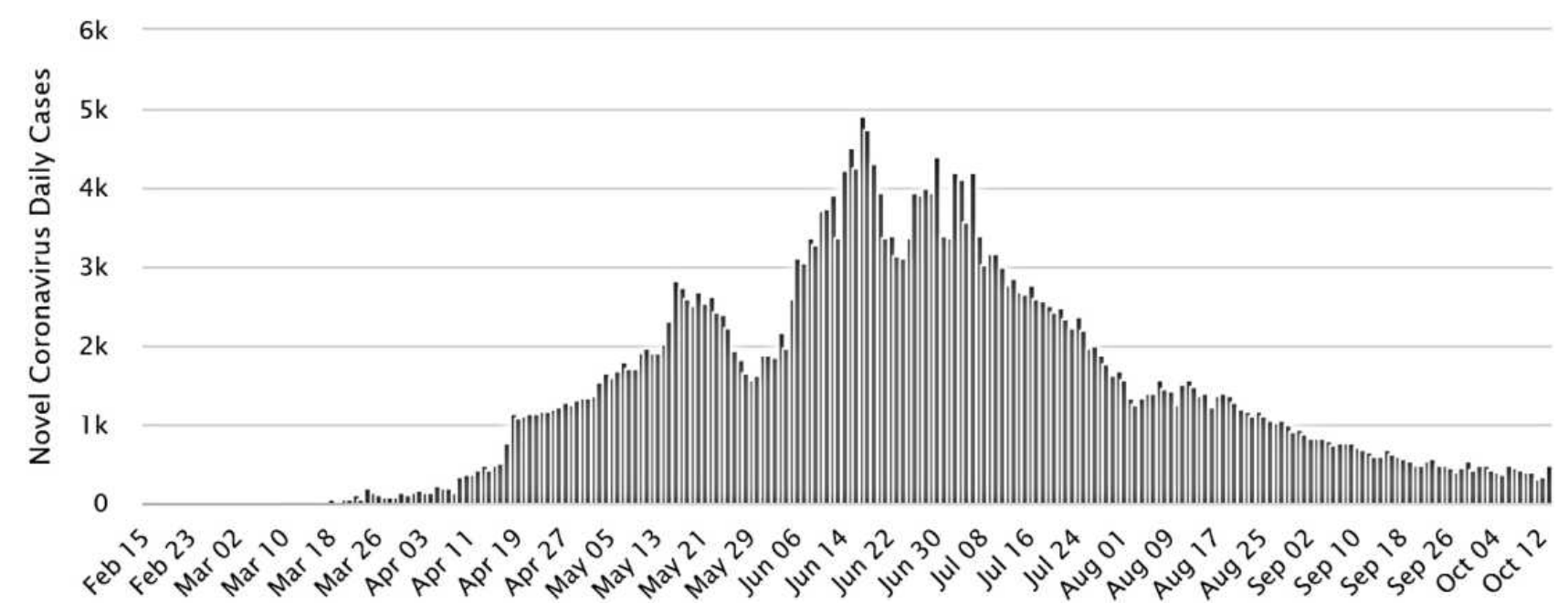

Figure I Daily new cases in Saudi Arabia.

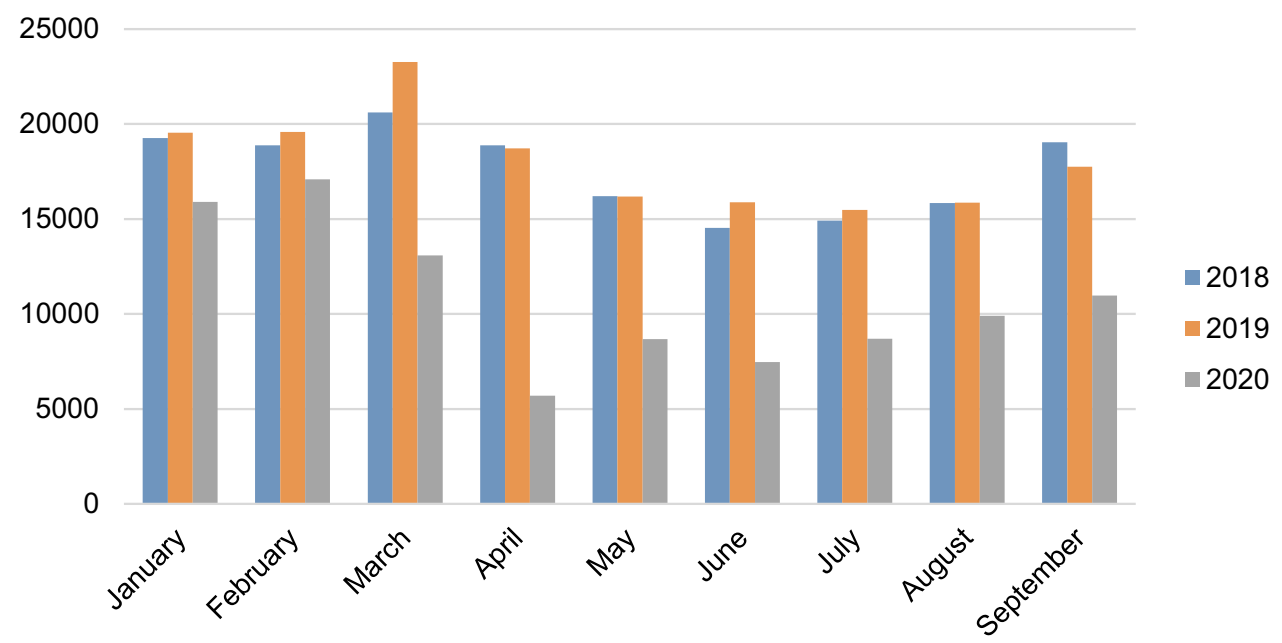

Figure 2 Number of patients visited the emergency room between 2018 to 2020 . 


\section{Materials and Methods}

Data were collected from an open access source at the private hospital in the capital of Saudi Arabia. ${ }^{11}$ The data are presented in Figure 2 which shows a significant reduction in the number of patients attending the ED in 2020 compared to the corresponding periods in 2018 and 2019. However, as shown in Table 1, the patient numbers follow similar trends each year, with a peak in the month of February (2020) or March (2018 and 2019). Paired t-tests with a $<5 \%$ p value were used to define statistical significance.

Table 2 presents descriptive statistics for 2018 and 2019 and Table 3 shows estimation for paired difference of the population mean for 2018 and 2019. While Table 4 presents descriptive statistics for 2019 and 2020 and Table 5 shows estimation for paired difference of the population mean for 2019 and 2020. Paired t-tests show no significant difference $(p=0.246)$ between the numbers of patients attending the ED

Table I Number of Patients Attending ED in 2018, 2019 and 2020 from January to September

\begin{tabular}{|l|l|l|l|}
\hline Year & $\mathbf{2 0 1 8}$ & $\mathbf{2 0 1 9}$ & $\mathbf{2 0 2 0}$ \\
\hline January & 19,254 & 19,537 & 15,908 \\
February & 18,882 & 19,591 & 17,079 \\
March & 20,616 & 23,257 & 13,079 \\
April & 18,878 & 18,719 & 5707 \\
May & 16,195 & 16,182 & 8687 \\
June & 14,540 & 15,887 & 7466 \\
July & 14,908 & 15,474 & 8704 \\
August & 15,844 & 15,863 & 9906 \\
September & 19,048 & 17,753 & 10,967 \\
\hline
\end{tabular}

Table 2 Descriptive Statistics for 2018 and 2019

\begin{tabular}{|l|c|c|c|c|}
\hline Sample & $\mathbf{N}$ & Mean & $\begin{array}{c}\text { Standard } \\
\text { Deviation }\end{array}$ & $\begin{array}{c}\text { Standard Error } \\
\text { Mean }\end{array}$ \\
\hline 2018 & 9 & 17,574 & 2204 & 735 \\
2019 & 9 & 18,029 & 2545 & 848 \\
\hline
\end{tabular}

Table 3 Estimation for Paired Difference of the Population Mean for 2018 and 2019

\begin{tabular}{|l|l|l|l|}
\hline Mean & $\begin{array}{l}\text { Standard } \\
\text { Deviation }\end{array}$ & $\begin{array}{l}\text { Standard } \\
\text { Error } \\
\text { Mean }\end{array}$ & $\begin{array}{l}\text { 95\% Confidence Level of } \\
\text { the Mean Differences } \mu_{-}\end{array}$ \\
\hline-455 & 1091 & 364 & $(-1294,384)$ \\
\hline
\end{tabular}

Table 4 Descriptive Statistics for 2019 and 2020

\begin{tabular}{|l|l|l|l|l|}
\hline Sample & N & Mean & $\begin{array}{l}\text { Standard } \\
\text { Deviation }\end{array}$ & $\begin{array}{l}\text { Standard Error } \\
\text { Mean }\end{array}$ \\
\hline 2019 & 9 & 18,029 & 2545 & 848 \\
2020 & 9 & 10,834 & 3831 & 1277 \\
\hline
\end{tabular}

Table 5 Estimation for Paired Difference of the Population Mean for 2019 and 2020

\begin{tabular}{|l|l|l|l|}
\hline Mean & $\begin{array}{l}\text { Standard } \\
\text { Deviation }\end{array}$ & $\begin{array}{l}\text { Standard } \\
\text { Error } \\
\text { Mean }\end{array}$ & $\begin{array}{l}\text { 95\% Confidence Level of } \\
\text { the Mean Differences } \mu_{-}\end{array}$ \\
\hline 7196 & 3179 & 1060 & $(4752,9639)$ \\
\hline
\end{tabular}

in 2018 and 2019, but a significant difference between attendance in 2019 and $2020(\mathrm{p}<0.001)$.

\section{Results and Discussion}

The private hospital under study classifies ED patients as adults, pediatric or obstetrics and gynecology, and investigations or treatments as shown in Table 6.

Since the number of patients attending the hospital's ED during the pandemic is statistically lower than the number visited the hospital's ED in the same period before the pandemic, this situation has several consequences such as an economic impact on the hospital and health impact on the community. ${ }^{6}$ As mentioned, this study will determine the type of patient categories with the greatest reduction in hospital attendance, and the impact, if any, of this reduction on community health. The study therefore aims to compare the characteristics of patients attending the hospital ED before and after the pandemic.

Table 6 Patient and Treatment Classifications

\begin{tabular}{|l|l|}
\hline Category & Classification \\
\hline 1 & New File (new ED patient) \\
2 & Old File (existing ED patient) \\
3 & Referrals \\
4 & Injection \\
5 & Nebulizer \\
6 & Follow Up \\
7 & Electrocardiogram \\
8 & Minor Surgery \\
9 & Plaster Cast \\
10 & Special Procedure \\
11 & Road Traffic Accidents (RTS) \\
12 & Other \\
\hline
\end{tabular}


Table 7 shows the number of existing adult hospital patients attending the hospital ED from January to September inclusive in 2019 and 2020. The difference between these attendance numbers was found to be significant based on a paired $t$ test $(\mathrm{p}=0.011)$.

The number of new adult files opened in the same periods in 2020 and 2019 are shown in Table 8. Overall, no significant difference was found between these attendance numbers $(\mathrm{p}=0.799)$. However, the table indicates an increase in May 2020 which may reflect COVID-19 virus testing during that month.

The numbers of existing pediatric patients attending the ED during 2019 and 2020, during the pandemic, are shown in Table 9. Overall, the numbers were found to the significantly lower in 2020 than in $2019(\mathrm{p}<0.001)$.

The number of new pediatric new patients attending the ED during these periods are shown in Table 10 . A statistically significant difference was found between the attendance numbers in these two years $(p<0.001)$.

Table 7 Shows the Number of Adult Patients with an Existing File Attending the ED

\begin{tabular}{|l|c|c|}
\hline Month & Old File in 2020 & Old File in 2019 \\
\hline Jan & 5536 & 5942 \\
Feb & 5900 & 14,330 \\
Mar & 5298 & 6949 \\
Apr & 2156 & 13,065 \\
May & 2824 & 5584 \\
Jun & 2415 & 5405 \\
Jul & 2714 & 5422 \\
Aug & 3408 & 5552 \\
Sep & 3765 & 5570 \\
\hline
\end{tabular}

Table 8 Shows the Number of New Adult Patients Attending the ED

\begin{tabular}{|l|c|c|}
\hline & New File in 2020 & New Files in 2019 \\
\hline Jan & 583 & 692 \\
Feb & 574 & 593 \\
Mar & 705 & 754 \\
Apr & 598 & 660 \\
May & 1895 & 639 \\
Jun & 472 & 721 \\
Jul & 623 & 732 \\
Aug & 588 & 628 \\
Sep & 540 & 637 \\
\hline
\end{tabular}

Table 9 Shows the Number of Existing Pediatric Patients Attending the ED

\begin{tabular}{|l|l|l|}
\hline Month & Old File in $\mathbf{2 0 2 0}$ & Old File in $\mathbf{2 0 1 9}$ \\
\hline Jan & 4340 & 6706 \\
Feb & 5192 & 7382 \\
Mar & 2868 & 9028 \\
Apr & 543 & 6078 \\
May & 861 & 4335 \\
Jun & 948 & 4199 \\
Jul & 1126 & 3464 \\
Aug & 1636 & 4046 \\
Sep & 2174 & 5383 \\
\hline
\end{tabular}

Table 10 Shows the Number of New Pediatric Patients Attending the ED

\begin{tabular}{|l|c|c|}
\hline Month & New File 2020 & New File 2019 \\
\hline Jan & 347 & $36 \mathrm{I}$ \\
Feb & 264 & 374 \\
Mar & 202 & 447 \\
Apr & 57 & 309 \\
May & 94 & 257 \\
Jun & 104 & 310 \\
Jul & 116 & 258 \\
Aug & 126 & 258 \\
Sep & 150 & 341 \\
\hline
\end{tabular}

\section{Conclusion}

This research has used data reflecting the periods before and during the COVID-19 pandemic to make a comparison of the number of patients attending an ED at a private hospital in the middle eastern region of Saudi Arabia. The data reveal reduced patient attendance at ED during the pandemic. Analysis of the results indicated that there was a difference in the volume of patients' attendance at the emergency room between the pre- and duringpandemic period. However, the differences in size are limited to a specific type of patient, being apparent in existing patients but not in new patients.

These findings may be explained by existing patients being accustomed to visiting the ED or believing that the risk of visiting the ED is less than that of non-attendance. The lack of significant reduction in new adult patients may indicate that true emergencies necessitated ED attendance for this group of patients.

As a result of this research, it should be clear that each healthcare facility based on its geographical location should evaluate the type of patients who have a difference in size reaching the emergency room. 
Healthcare facilities should establish measures to monitor ED attendance by different patient groups in order to determine whether interventions should be introduced to improve access to care. For example, a decrease in the number of children in the category of "injection" or "nebulizer" should trigger contact with their parents to discuss the non-attendance.

In summary, this study indicates that there is a difference between the number of cases attending health facility emergency departments before and after the COVID-19 pandemic, but this difference does not apply to all patient groups. Reasons for non-attendance may include fear of disease transmission within the ED or a tendency not to make non-essential visits to ED. Further research is needed to explore the reasons for ED non-attendance using questionnaire methods to collect data that may lead to changes in state or health facility policy and thus may prevent negative consequences of ED non-attendance.

\section{Ethical Approval}

The ethics committee in the Engineering Management Department at Prince Sultan University have exempted this study from requiring ethical approval. The committee confirm that there is no need for any approval since the data is in form of retrospective, available in public domain and it is in the form of numbers which does not reveal any personal information.

\section{Acknowledgments}

The author would like to thank Prince Sultan University for the financial support they provided to produce this research.

\section{Disclosure}

The author declares no known competing financial interests or personal relationships with the potential to influence the work reported in this paper.

\section{References}

1. Rehmani R, Norain A. Trends in emergency department utilization in a hospital in the Eastern region of Saudi Arabia. Saudi Med J. 2007;28:236-240.

2. Moore BJ, Stocks C, Owens PL. Trends in Emergency Department Visits, 2006-2014. Rockville: Agency for Healthcare Research and Quality; 2017.

3. Unwin M, Kinsman L, Rigby S. Why are we waiting? Patients' perspectives for accessing emergency department services with nonurgent complaints. Int Emerg Nurs. 2016;29:3-8. doi:10.1016/j. ienj.2016.09.003

4. Dawoud SO, Ahmad AMK, Alsharqi OZ, Al-Raddadi RM. Utilization of the emergency department and predicting factors associated with its use at the Saudi Ministry of Health General Hospitals. Glob J Health Sci. 2015;8:90-106. doi:10.5539/gihs.v8n1p90

5. Alyasin A, Douglas C. Reasons for non-urgent presentations to the emergency department in Saudi Arabia. Int Emerg Nurs. 2014;22:220-225. doi:10.1016/j.ienj.2014.03.001

6. Alodan A, Alalshaikh G, Alqasabi A, Alomran S, Abdelhadi A, Alkhayyal A. Studying the efficiency of waiting time in outpatient pharmacy. MethodsX. 2020;7. doi:10.1016/j.mex.2020.100913

7. Alumran A, Alkhaldi O, Aldroorah Z, Alsayegh Z, Alsafwani F, Almaghraby N. Utilization of an electronic triage system by emergency department nurses. J Multidiscip Healthc. 2020;13:339-344. doi:10.2147/JMDH.S250962

8. Hossain MA, Rashid MUB, Khan MAS, Sayeed S, Kader MA, Hawlader MDH. Healthcare workers' knowledge, attitude, and practice regarding personal protective equipment for the prevention of COVID-19. J Multidiscip Healthc. 2021;14:229-238. doi:10.2147/ JMDH.S293717

9. World Health Organization. Rational use of Personal Protective Equipment (PPE) for Coronavirus Disease (COVID-19): interim guidance; 2020. Available from: https://apps.who.int/iris/handle/ 10665/331695. Accessed January 11, 2021.

10. Alanzi TA. Review of mobile applications available in the app and google play stores used during the COVID-19 Outbreak. J Multidiscip Healthc. 2021;14:45-57. doi:10.2147/JMDH.S285014

11. Alqahtani JS, Mendes RG, Aldhahir A, et al. Global current practices of ventilatory support management in COVID-19 Patients: an International Survey. J Multidiscip Healthc. 2020;13:1635-1648. doi:10.2147/JMDH.S279031

\section{Publish your work in this journal}

The Journal of Multidisciplinary Healthcare is an international, peerreviewed open-access journal that aims to represent and publish research in healthcare areas delivered by practitioners of different disciplines. This includes studies and reviews conducted by multidisciplinary teams as well as research which evaluates the results or conduct of such teams or healthcare processes in general. The journal covers a very wide range of areas and welcomes submissions from practitioners at all levels, from all over the world. The manuscript management system is completely online and includes a very quick and fair peer-review system. Visit http://www.dovepress.com/testimonials. php to read real quotes from published authors. 